\title{
Adequacy of standards for kick impact in the Taekwondo electronic scoring system: Comparison of a reference group model based on empirical data
}

\section{Chang-Hwan Choi}

Kangwon National University

Minsoo Jeon

Korea National Sport University

Hyeri Oh ( $\nabla$ simbi0430@naver.com )

CHA University

\section{Research Article}

Keywords: Kick Impact, Protector, Scoring Systems, Reference Group Model, Sports Analytics, Martial Arts

Posted Date: February 23rd, 2021

DOI: https://doi.org/10.21203/rs.3.rs-155834/v1

License: (a) This work is licensed under a Creative Commons Attribution 4.0 International License.

Read Full License 


\section{Abstract}

Background: In Taekwondo competitions, the rule is that points are scored when the impact of the kick reaches a predetermined threshold of strength. This study aimed to explore the adequacy of the protector and scoring system (PSS) designed to determine Taekwondo body scoring based on a reference group model (RGM). Specifically, the kicking impact of the PSS was calculated using data from 188 matches fought during of 2018 Jakarta Asian Games. The RGM was designed based on empirical data by classifying the victory and defeat groups by gender and weight class, and the scoring method was set according to these criteria.

Result: The result of this study are as follows. First, there was no difference in the average impact of kicks of Taekwondo players by weight class. Second, as a result of setting up the kick scoring impact standards of Taekwondo PSS by classifying the winning and non-winning groups, the kickscoring impact set by the WTF was found to be high in all weight classes except -58 kg.Lastly, as a result of comparing the settings of impact to score according to weight classes, the kick scoring impact standard set by the WTF was higher in heavyweight (men's: under-80kg, $+80 \mathrm{~kg}$, women's: under-67kg, over-67kg) than in the lightweight (men's: under-58kg, under-63kg, under-68kg, women's: under $49 \mathrm{~kg}$, under53kg, under $57 \mathrm{~kg}$ ).

Conclusion: The kick scoring impact set by the WTF was found to be high in all weight classes except for the under $58 \mathrm{~kg}$ class, as a result of defining kick scoring impact based on the standards of WTF-certified PSS by classifying the matches into winning and non-winning groups. Finally, as a result of comparing the scoring impact settings according to weight class, the kick scoring impact standard set by the WTF was higher for the heavier weight classes than for the lighter weight classes.

\section{Introduction}

Taekwondo is a sport that attracts many people and it is becoming a popular sport practiced worldwide. Furthermore, Taekwondo was adopted as an Olympic sport where only the best athletes participate. In this regard, the World Taekwondo Federation (WTF) is making various efforts to improve the sport of Taekwondo, for example by assessing the fairness of the scoring system which is a currently an issue in Taekwondo competitions.

Changes in the scoring method are being implemented to ensure fairness in Taekwondo matches. In the past, the scores were determined based on the subjective judgment of the referees (Cho \& Eom, 2007). However, the protector and scoring system (PSS) was developed and introduced in order to addressproblemswiththe scoring method encountered in the past. PSS sets scoring criteria according to the kick impact determinedin advance formale and female weight classes, and automatically calculates the score when the scoring area is hit harderthan the set kick impact threshold (World Taekwondo Federation, 2019). The benefit of setting a kick impact scoring thresholdis that the higher the weight class, the higher the kick impact standard. In this regard, Taekwondo is applying a more objectiveand consistent scoringtool than in the past (Cho, Jung, Kang, Kim, \& Kwak, 2009), contributing to its becoming a global sport. 
However,theTaekwondo PSS can present several problems despite its advantages. Furthermore, the validity of the kick impact scoring standard remains unclear, even though its objectivity and consistency were improved. Currently, the WTF has arbitrarily set the kick impact scoring scalefor maleand femaleweight classes under an expert's subjective judgment (Lee, 2016). Furthermore, it is necessary to establish the basis for different impact settings,according to weight class. For example, in the case of males, the scoring impact of the under-58kg weight class was set to 18 levels, that of the under$63 \mathrm{kgweight}$ class was set to 20 levels, and that of the under-68kgweight class was set to 21 levels. Despite the same $5 \mathrm{~kg}$ difference, the under-58kg and under-63kgweight classes have a difference of twolevels, while the under-63kg and under-68kgweight classes have a difference of one level (Choi \& Jeon, 2019). These differences in setting kick impact leads todoubt inboth the players and the coaches. In fact, a difference of one level is not great, but due to the nature of Taekwondo, where the criteria for judging scores are based on a reference-oriented evaluation, itcould lead to skewedresults. Moreover, studies on setting kick scoring impact are continuously requiredbecause it can be an important factor affecting score, game flow, and player results. Research on Taekwondo PSS hasbeen conducted on the score sensor and satisfaction withthe PSS (Kim \& Baek, 2015; Yang, 2010; Tasika, 2013; Ramazanoglu, 2013), and these studies have calculatedthe difficulty of assessing kick impact by weight class (Choi \& Jeon, 2019). Thus, studies on setting kick scoring impact arerequired. This study aimedto confirm the adequacy of setting akick impact standard forTaekwondo PSS. Specifically, we analyzed the difference between the kick impact standard set by the WTF and the kick impact standard based on kick impact data fromthe 2018 Jakarta Asian Games. Duringthis process, weverified whether the kicking standard currently applied was high or low.

\section{Methods}

\subsection{Research Data}

In this study, the adequacy of akick impact standard by weight class was confirmed using 2018 Jakarta Asian Games Taekwondo match data. Specifically, there werea total of 104 matches (under-58kg weight class: 24 matches, under-63kgweight class: 25 matches, under-68kgweight class: 21 matches, under80kgweight class: 20 matches, and over-87kgweight class: 14 matches), with a maximum of 26 countries and a minimum of 21 countries. For women's matches, there werea total of 84 matches (under49kgweight class: 16 matches, under-53kgweight class: 17 matches, under-57kgweight class: 19 matches, under-67kgweight class: 15 matches, over-67kgweight class: 17 matches), with a maximum of 26 countries and a minimum of 15 countries(table 1 ). 
Table 1. Taekwondo Men's and Women's matchesby weight class and participating country

\begin{tabular}{|c|c|c|c|c|c|}
\hline \multicolumn{3}{|c|}{ Men's } & \multicolumn{3}{|c|}{ Women's } \\
\hline $\begin{array}{l}\text { Weight } \\
\text { Class }\end{array}$ & $\begin{array}{l}\text { Number of } \\
\text { games(\%) }\end{array}$ & $\begin{array}{l}\text { Number of } \\
\text { Participating } \\
\text { Countries }\end{array}$ & $\begin{array}{c}\text { Weight } \\
\text { Class }\end{array}$ & $\begin{array}{l}\text { Number of } \\
\text { games (\%) }\end{array}$ & $\begin{array}{l}\text { Number of } \\
\text { Participating } \\
\text { Countries }\end{array}$ \\
\hline Under58kg & $24(23.1)$ & 26 & $\begin{array}{l}\text { Under } \\
49 \mathrm{~kg}\end{array}$ & $16(19.1)$ & 17 \\
\hline Under63kg & $25(24.0)$ & 26 & $\begin{array}{l}\text { Under } \\
53 \mathrm{~kg}\end{array}$ & $17(20.2)$ & 18 \\
\hline Under68kg & $21(20.2)$ & 22 & $\begin{array}{l}\text { Under } \\
57 \mathrm{~kg}\end{array}$ & $19(22.6)$ & 20 \\
\hline $\begin{array}{l}\text { Under } \\
80 \mathrm{~kg}\end{array}$ & $20(19.2)$ & 21 & $\begin{array}{l}\text { Under } \\
67 \mathrm{~kg}\end{array}$ & $15(17.9)$ & 16 \\
\hline Over $80 \mathrm{~kg}$ & $14(13.5)$ & 21 & $\begin{array}{l}\text { Over } \\
67 \mathrm{~kg}\end{array}$ & $17(20.2)$ & 15 \\
\hline Total & $104(100)$ & & Total & $84(100)$ & \\
\hline
\end{tabular}

\subsection{DataAcquisition Procedure}

In this study, data from KP\&P PSSobtainedin the 2018 Jakarta Asian Games Taekwondo matcheswere provided by the Asian Taekwondo Federation and KP\&P. This is a score that can be publicly confirmed as the PSS score generated in the game. The KP\&P PSS is an official accreditation body certified by the WTF (October 23, 2012) and it is the official scoring system used in world competitions and Asian Games.

Only the scoring impact generated in the trunk area was entered and classified by weight classin order to use the data forthe scoring impact calculated by KP \&PPSS as research data. Data was input by threeTaekwondo match analysis experts to minimize error. Several matches were randomly selected and re-recorded to confirm the match with the previous record,after enteringthe data. The PSS kicking impact calculated through this process was 2,286 times for men (scoring frequency: 814 times, effective hit frequency: 1430), and 1,389 times for women(scoring frequency: 650 times, effective hit frequency: 688 times), and these values were used as research data.

\subsection{Group Classification for Establishing Kick Impact Reference Pointsfor the Protector and Scoring System}

Thecriterion groups model, one of the empirical methods, was usedin this studyto confirm the adequacy of the Taekwondo PSS kick impact reference point. The reference group model is divided into the group that meets the criteria and the onthat does not. The intersection point of the distribution of scores of the two groups was set as the reference point (Popham, 1990). Therefore, twomethods were used in this study to classify the group to determine the appropriateness of the kick impact reference. First, the winning group (which met the criteria) and the non-winning group (which did not meet the criteria), according to weight category, were divided and compared with the reference point shown at the intersection point of the 2-group score distributions with the kick impact reference point currently applied by WTF. Then, after 
classifying the groups according toweight class, the score distribution intersection point was identified. For example, for men's weight classes, the current kick impact reference point is determined by checking and comparing the intersection of the score distributions for the twogroups in the following order: under$58 \mathrm{~kg}$, and under- $63 \mathrm{~kg}$, under- $63 \mathrm{~kg}$ and under- $68 \mathrm{~kg}$, under- $68 \mathrm{~kg}$ and under-80kg, under-80kg, andover$80 \mathrm{kgweight}$ classes.

\subsection{Data Processing Method}

The descriptive statistics forthe PSS kick scoring impact were calculatedby weight class. Cutoff scores were calculated to establish scoring criteria according to the reference group. The cutoff score was calculated based on the standard normal distribution using the mean and standard deviation of the kicking intensities of the winning and non-winning groups according togender and weight. Furthermore, the intersection of the kicking intensity distributions of the winning and non-winning groups was selected as the cutoff score (Kaftandjieva, 2010). The accuracy of the classification was calculated to verify the validity of the scoring criteria through the cutoff score (Morrow, Mood, Disch, \& Kang, 2015). R program (ver 3.6.1) and MS-Excel were used for data analysis.

\section{Results}

\subsection{Basic Information on Kick Force of Top Taekwondo Athletes}

Figures 1 and2 showthe graphsofthe kick scoring impact by gender and weight class. As a result, the incidence of kick impact was high, between 10 to 20 levels, in both the men's and women'sdivisions. Also, regardless of weight class, the form of kick impact was shown as static distribution. Specifically,as shownin Table 2, for the men's under-58kg weight class, the average kicking impact was 18.4 levels, and 18.7 levelsfor the over-80kg weight class. Inthewomen's division, the average kick impact for theunder$49 \mathrm{~kg}$ weight class was 16.1 levels, and 17.3 levelsfor the over-67kg weight class.

Table 2. Results of protector and scoring system descriptive statistics by gender and weight class $(\mathrm{M} \pm \mathrm{SD})$

\begin{tabular}{|c|c|c|c|c|c|c|c|}
\hline \multicolumn{3}{|c|}{ Men } & \multicolumn{5}{|c|}{ Women } \\
\hline $\begin{array}{c}\text { Weight } \\
\text { Class }\end{array}$ & $\begin{array}{l}\text { Scoring } \\
\text { Group }\end{array}$ & $\begin{array}{l}\text { Effective } \\
\text { Hit Group }\end{array}$ & Total & $\begin{array}{l}\text { Weight } \\
\text { Class }\end{array}$ & $\begin{array}{c}\text { Scoring } \\
\text { Group }\end{array}$ & $\begin{array}{l}\text { Effective } \\
\text { Hit Group }\end{array}$ & Total \\
\hline Under58kg & $24.6 \pm 7.17$ & $13.6 \pm 1.88$ & $18.4 \pm 7.37$ & $\begin{array}{l}\text { Under } \\
49 \mathrm{~kg}\end{array}$ & $19.9 \pm 3.41$ & $12.7 \pm 1.39$ & $16.1 \pm 4.41$ \\
\hline Under63kg & $28.3 \pm 8.51$ & $14.7 \pm 2.40$ & $20.6 \pm 8.93$ & $\begin{array}{l}\text { Under } \\
53 \mathrm{~kg}\end{array}$ & $21.2 \pm 3.95$ & $13.2 \pm 1.73$ & $16.0 \pm 4.70$ \\
\hline Under68kg & $27.4 \pm 7.59$ & $15.1 \pm 2.65$ & $19.7 \pm 7.82$ & $\begin{array}{l}\text { Under } \\
57 \mathrm{~kg}\end{array}$ & $25.4 \pm 7.67$ & $13.3 \pm 1.71$ & $19.1 \pm 8.10$ \\
\hline $\begin{array}{l}\text { Under } \\
80 \mathrm{~kg}\end{array}$ & $32.2 \pm 8.62$ & $16.1 \pm 3.39$ & $21.4 \pm 9.44$ & $\begin{array}{l}\text { Under } \\
67 \mathrm{~kg}\end{array}$ & $25.5 \pm 5.82$ & $14.3 \pm 2.59$ & $17.3 \pm 6.17$ \\
\hline Over $80 \mathrm{~kg}$ & $30.9 \pm 7.70$ & $16.4 \pm 3.68$ & $18.7 \pm 6.99$ & $\begin{array}{l}\text { Over } \\
67 \mathrm{~kg}\end{array}$ & $27.3 \pm 4.37$ & $15.2 \pm 3.29$ & $17.3 \pm 5.71$ \\
\hline
\end{tabular}


3.2. Setting and Conducting Validity Testsfor theReference Points of Kick Scoring Impact for Top Taekwondo Playersinthe Protector and Scoring System

3.2.1. Setting kick impact reference points by gender and weight classes (classifiedaccording to thewinning and non-winning groups)

Table 3 showsthe criteria for kick impacts in the PSS by gender and weight classes. The groups are divided into winning and non-winning groupsin order to set the kick scoring impact criteria. As a result, formales, the under-58kgweight classwas 18 levels (acc:.365), the under-63kgweight classwas 19 levels (acc:.482), the under-68kgweight classwas 19 levels (acc:.494), the under-80kgweight classwas 19 levels (acc:.445), and the over-80kg weight classwas 20 levels (acc:.496). In the case of the over-80kgweight class, the classification accuracy was equal to.496 at 19 and 20 levels, but itwas determinedthat it is more reasonable to set the impactto 20 levels when looking at the sensitivity index for validity, where 19 levels:.674 and 20 levels:.689. In women, the classification accuracy was as follows: under $46 \mathrm{~kg}$ at 15 levels (acc:.489), under-53kg at 15 levels (acc:.525), under-57kg at 17 levels (acc:.498), under-67kg at 16 levels (acc:.443), and over-67kg at 18 levels (acc:.473). Kick scoring impact, which is divided into the winning and non-winning groups, was set lower than thatset by the WTF. 
Table 3.Kick scoring impact setting standards and their validations (group classification based on winning and non-winning groups)

\begin{tabular}{|c|c|c|c|c|c|c|c|c|c|}
\hline \multicolumn{5}{|c|}{ Men } & \multicolumn{5}{|c|}{ Women } \\
\hline $\begin{array}{c}\text { Weight } \\
\text { Class }\end{array}$ & A & B & Valic & Index & $\begin{array}{c}\text { Weight } \\
\text { Class }\end{array}$ & A & B & Valid & Index \\
\hline \multirow{3}{*}{$\begin{array}{c}\text { Under } \\
58 \mathrm{~kg}\end{array}$} & \multirow{3}{*}{18} & \multirow{3}{*}{18.8} & 18 & .365 & \multirow{3}{*}{$\begin{array}{c}\text { Under } \\
49 \mathrm{~kg}\end{array}$} & \multirow{3}{*}{16} & \multirow{3}{*}{16.0} & 15 & .489 \\
\hline & & & 19 & .329 & & & & 16 & .466 \\
\hline & & & 20 & .309 & & & & 17 & .454 \\
\hline \multirow{3}{*}{$\begin{array}{c}\text { Under } \\
63 \mathrm{~kg}\end{array}$} & \multirow{3}{*}{20} & \multirow{3}{*}{20.4} & 19 & .482 & \multirow{3}{*}{$\begin{array}{c}\text { Under } \\
53 \mathrm{~kg}\end{array}$} & \multirow{3}{*}{17} & \multirow{3}{*}{16.0} & 15 & .525 \\
\hline & & & 20 & .464 & & & & 16 & .499 \\
\hline & & & 21 & .426 & & & & 17 & .485 \\
\hline \multirow{3}{*}{$\begin{array}{l}\text { Under } \\
68 \mathrm{~kg}\end{array}$} & \multirow{3}{*}{21} & \multirow{3}{*}{19.3} & 18 & .486 & \multirow{3}{*}{$\begin{array}{l}\text { Under } \\
57 \mathrm{~kg}\end{array}$} & \multirow{3}{*}{18} & \multirow{3}{*}{18.0} & 17 & .498 \\
\hline & & & 19 & .494 & & & & 18 & .486 \\
\hline & & & 20 & .478 & & & & 19 & .475 \\
\hline \multirow{3}{*}{$\begin{array}{l}\text { Under } \\
80 \mathrm{~kg}\end{array}$} & \multirow{3}{*}{23} & \multirow{3}{*}{19.5} & 19 & .445 & \multirow{3}{*}{$\begin{array}{c}\text { Under } \\
67 \mathrm{~kg}\end{array}$} & \multirow{3}{*}{20} & \multirow{3}{*}{17.3} & 16 & .443 \\
\hline & & & 20 & .423 & & & & 17 & .433 \\
\hline & & & 21 & .401 & & & & 18 & .382 \\
\hline \multirow{3}{*}{$\begin{array}{l}\text { Over } \\
80 \mathrm{~kg}\end{array}$} & \multirow{3}{*}{25} & \multirow{3}{*}{19.0} & 18 & .458 & \multirow{3}{*}{$\begin{array}{l}\text { Over } \\
67 \mathrm{~kg}\end{array}$} & \multirow{3}{*}{22} & \multirow{3}{*}{16.8} & 17 & .462 \\
\hline & & & 19 & .496 & & & & 18 & .473 \\
\hline & & & 20 & .496 & & & & 19 & .467 \\
\hline
\end{tabular}

\section{A : Kick impact standards officially established by the World Taekwondo Federation \\ B : Kick impact standards set in this study}

\subsubsection{Setting men's and women's kick impact reference points (by weight classes)}

Table 4 showsthe kick impact criteria of the PSSaccording to men's and women's weight classes. Weight class was divided based on weight classin order to set the kick scoring impact. As a result, for men under58kg and under63kg, 21 levels (acc:.622), under63kg and under68kg, 21 levels (acc:.492), under68kg and under80kg, 22 levels, and under80kg and over $80 \mathrm{~kg}$, 21levels (acc:.502). Forwomen, under49kg and under53kg, 15 levels (acc:,468), under53kg and under57kg, 19 levels (acc:.610), under57kg and under67kg, 17 levels (acc:.448), and under67kg and over67kg, 18 levels (acc:.572). When dividingthe kick scoring impactinto weight classes, it was found to be higher than the kick scoring impact currently applied in most heavyweight classes. 
Table 4.Kick scoring impact setting standards and their validations (group classification based on weight class)

\begin{tabular}{|c|c|c|c|c|c|c|c|c|c|}
\hline \multicolumn{5}{|c|}{ Men } & \multicolumn{5}{|c|}{ Women } \\
\hline \multirow[t]{2}{*}{ Weight class } & \multirow[t]{2}{*}{ A } & \multirow[t]{2}{*}{ B } & \multicolumn{2}{|c|}{ Validity Index } & \multirow[t]{2}{*}{ Weight Class } & \multirow[t]{2}{*}{ A } & \multirow[t]{2}{*}{ B } & \multicolumn{2}{|c|}{ Validity Index } \\
\hline & & & 19 & .609 & & & & 15 & .468 \\
\hline Under $58 \mathrm{~kg}$ & 18 & & & & Under $49 \mathrm{~kg}$ & 16 & & & \\
\hline & & 19.5 & 20 & .615 & & & 16.0 & 16 & .436 \\
\hline \multirow[t]{3}{*}{ Under $63 \mathrm{~kg}$} & 20 & & & & Under $53 \mathrm{~kg}$ & 17 & & & \\
\hline & & & 21 & .622 & & & & 17 & .412 \\
\hline & & & 19 & .479 & & & & 17 & .605 \\
\hline \multirow[t]{2}{*}{ Under $63 \mathrm{~kg}$} & 20 & & & & Under $53 \mathrm{~kg}$ & 17 & & & \\
\hline & & 20.1 & 20 & .480 & & & 17.5 & 18 & .608 \\
\hline
\end{tabular}

\begin{tabular}{|c|c|c|c|c|c|c|c|c|}
\hline \multirow[t]{2}{*}{ Under $68 \mathrm{~kg}$} & \multirow[t]{2}{*}{21} & & & \multirow[t]{2}{*}{ Under $57 \mathrm{~kg}$} & \multirow{2}{*}{\multicolumn{2}{|c|}{18}} & \multirow[b]{2}{*}{19} & \multirow[b]{2}{*}{.610} \\
\hline & & 21 & .492 & & & & & \\
\hline & & 20 & .522 & & & & 17 & .448 \\
\hline Under $68 \mathrm{~kg}$ & 21 & & & Under $57 \mathrm{~kg}$ & 18 & & & \\
\hline & 20.5 & 21 & .516 & & & 18.2 & 18 & .434 \\
\hline
\end{tabular}

\begin{tabular}{|c|c|c|c|c|c|c|c|c|c|}
\hline \multirow[t]{2}{*}{ Under $80 \mathrm{~kg}$} & \multirow{2}{*}{\multicolumn{2}{|c|}{23}} & & & \multirow[t]{2}{*}{ Under $67 \mathrm{~kg}$} & \multirow{2}{*}{\multicolumn{2}{|c|}{20}} & \multirow[b]{2}{*}{19} & \multirow[b]{2}{*}{.426} \\
\hline & & & 22 & .526 & & & & & \\
\hline \multirow{3}{*}{ Under $80 \mathrm{~kg}$} & & & 19 & .459 & & & & 16 & .530 \\
\hline & 23 & & & & Under $67 \mathrm{~kg}$ & 20 & & & \\
\hline & & 20.0 & 20 & .473 & & & 17.3 & 17 & .541 \\
\hline
\end{tabular}

Over $87 \mathrm{~kg} \quad 25$

Over $67 \mathrm{~kg} \quad 22$

$\begin{array}{llll}21 & .502 & & \\ 18 & .572\end{array}$
A : Kick impact standards officially established by the World Taekwondo Federation
B : Kick impact standards set in this study

\section{Discussion}

The introduction of PSS to Taekwondo was attractive to many coaches, athletes, and researchers. PSS is a measuring tool that determines whether a player scores during a match. Research onthevalidity and adequacy of the tool has been conducted continuously (Morrow, Mood, Disch, \& Kang, 2015). However, the criteria for determining the score in PSS, that is, research on the setting of the kick score impact is insufficient. Currently, the kick score impact setting is set by subjective judgment, thus leaving doubts. Therefore, this study was performed to confirm the adequacy of the setting of the impact of the kick protector for PSS.

First, as a result of confirming the form of impact of the PSS kick according to men's and women's weight class, it was confirmed that both men and women have similar patterns regardless of weight class. 
Especially, when comparing the average kick impact by weight class, it was determinedthat the difference in kick impact was not significant. In the current WTF guidelines, the scoring impact for kicks is set higher for higher weight classes. Previous studies also reported that scoringfrequency was relatively low inhigher weight classes than in lower weight classes, pointing to the same problem of setting the scoring strength forkicks (Choi \& Jeon, 2019).

Furthermore, this study utilizes survey data to calculate and compare the PSS kick scoring impact reference point. As a result, it was confirmed that in both methods of calculating the reference point, the weighted kick score setting was set higher than the currently set kick score. In fact, it is generallymore logical to set a higher kick scoring impact for ahigher weight class. However, considering that there is movement of the opponent player when being kicked and the kicks are defended by hand, setting a graded kick scoring impact isamatter of concern.

On the other hand, the kick scoring impact criteria suggested in the study results and the kick scoring impact set by the WTF differs by 4 levels to 1 level. In fact, although a 1-level difference might seem small, it can still affect the score, and accordingly change the result. Since Taekwondo has such characteristics, it is inevitable to emphasize the importance ofsetting the kick scoring impact of PSS.

Finally, the kick scoring impact setting in men's and women's different weight classes isdependent on the method and, thus, the limitations were that there are no clear standard of setting kick scoring impact (e.g. the kick scoring impact standard was under53kg: 15 levels, under $57 \mathrm{~kg}: 17$ levels, and under67kg: 16 levels, showing that higher weight classes havealower standard of kick scoring impact). In addition, only the Asian Games data wereused, which can be interpreted as results for specific regions. Nevertheless, it is certain that this study provides basic data that could solve the problem of setting the kick scoring impact suggested by the WTF. Also, this study attempted to identify the problem and solve it by using nonsubjective data in setting the kick scoring impact, which may be used as important information in the future. Subsequent studies should focus on experts setting kick scoring impact according to the data results, whichcould be used as a more valid measure of athleticperformance.

\section{Conclusion}

This study confirmed the adequacy of setting the scoring impact of Taekwondo kicks. The conclusions of this study are as follows. First, there was no difference in the average impact of kicks of Taekwondo players by weight class. Second, as a result of setting up the kick scoring impact standards of Taekwondo PSS by classifying the winning and non-winning groups, the kickscoring impact set by the WTF was found to be high in all weight classes except $-58 \mathrm{~kg}$.Lastly, as a result of comparing the settings of impact to score according to weight classes, the kick scoring impact standard set by the WTF was higher in heavyweight (men's: under-80kg, $+80 \mathrm{~kg}$, women's: under- $67 \mathrm{~kg}$, over- $67 \mathrm{~kg}$ ) than in the lightweight (men's: under-58kg, under-63kg, under-68kg, women's: under $49 \mathrm{~kg}$, under $53 \mathrm{~kg}$, under $57 \mathrm{~kg}$ ).

\section{Declarations}




\section{-Declarations}

Not applicable

\section{-Consent for publication}

Not applicable

\section{-Availability of data and materials}

-The format of the data is recorded in Excel, and is provided upon request to the corresponding author.

\section{Competing interests}

Not applicable

\section{-Funding}

Not applicable

\section{-Ethics approval and consent to participate}

Not applicable

\section{-Authors' contributions}

1. Study concept and design: Chang-Hwan Choi, Heyri Oh

2. Acquisition of data: Chang-Hwan Choi, Heyri Oh

3. Analysis and interpretation of data: Minsoo Jeon

4. Drafting of the manuscript: Minsoo Jeon, Heyri Oh

5. Critical revision of the manuscript for important intellectual content: Heyri Oh

6. Statistical analysis: Minsoo Jeon

7. Administrative, technical, and material support: Minsoo Jeon

8. Study supervision: Chang-Hwan Choi

\section{-Acknowledgements}

Not applicable

\section{References}

1. Cho, E.H.;Eom, H.J. Validity of electronic-protector scoring system in Taekwondo Games. he Korean J Meas Eval Phys Educ Sports Sci2007, 9, 93-104. 
2. Cho, E.H.; Jung, M.M.; Kang, S.K.; Kim, J.H.;Kwak, T.Y. Data analysis of Taekwondo games decision by Intraclass correlation coefficient: Electronic Protector vs Judgement score. The Journal of Korean Alliance of Martial Arts2009, 11, 165-176.

3. Choi, C.;Jeon, M. Appropriateness of setting kick scoring impact by taekwondo certified Protector and Scoring Systems: comparison of difficulty of male and female weight class applying Rash model, Arch Budo2019, 15.

4. Kaftandjieva, F. Methods for setting cut scores in criterion-referenced achievement tests. Cito, Arnhem: EALTA2010, 170.

5. Kin, B.G.;Baek, W.Y. Structural relationship among user experience, flow and satisfaction of electronic hogu system in the Taekwondo game. Korean journal of physical education2015, 54, 299-312.

6. Lee, Y.R. The difference in force measurements between the electronic chest protectors in Taekwondo. Taekwondo Research Institute of Kukkiwon2016, 7, 119-134.

7. Morrow Jr, J.R.; Mood, D.; Disch, J.;Kang, M. Measurement and evaluation in human performance, $5 \mathrm{E}$. Human Kinetics2015.

8. Popham, W.J. Modern educational measurement: A practitioner's perspective. IOX Assessment Associates 1990.

9. Ramazanoglu, N. Transmission of impact through the electronic body protector in taekwondo.International Journal of Applied2013, 3.

10. Tasika, N. Reliability \& linearity of an electronic body protector employed in taekwondo games: a preliminary study 2013.

11. World Taekwondo (2019). Retrieved March 5, 2018 from http://www.worldtaekwondo.org.

12. Yang, J.S. A Study on the Satisfaction with Electronic Protector and Revised Game Rules in High School Taekwondo Athletes. The Journal of Korean Alliance of Martial Arts2010, 54, 299-312.

\section{Figures}




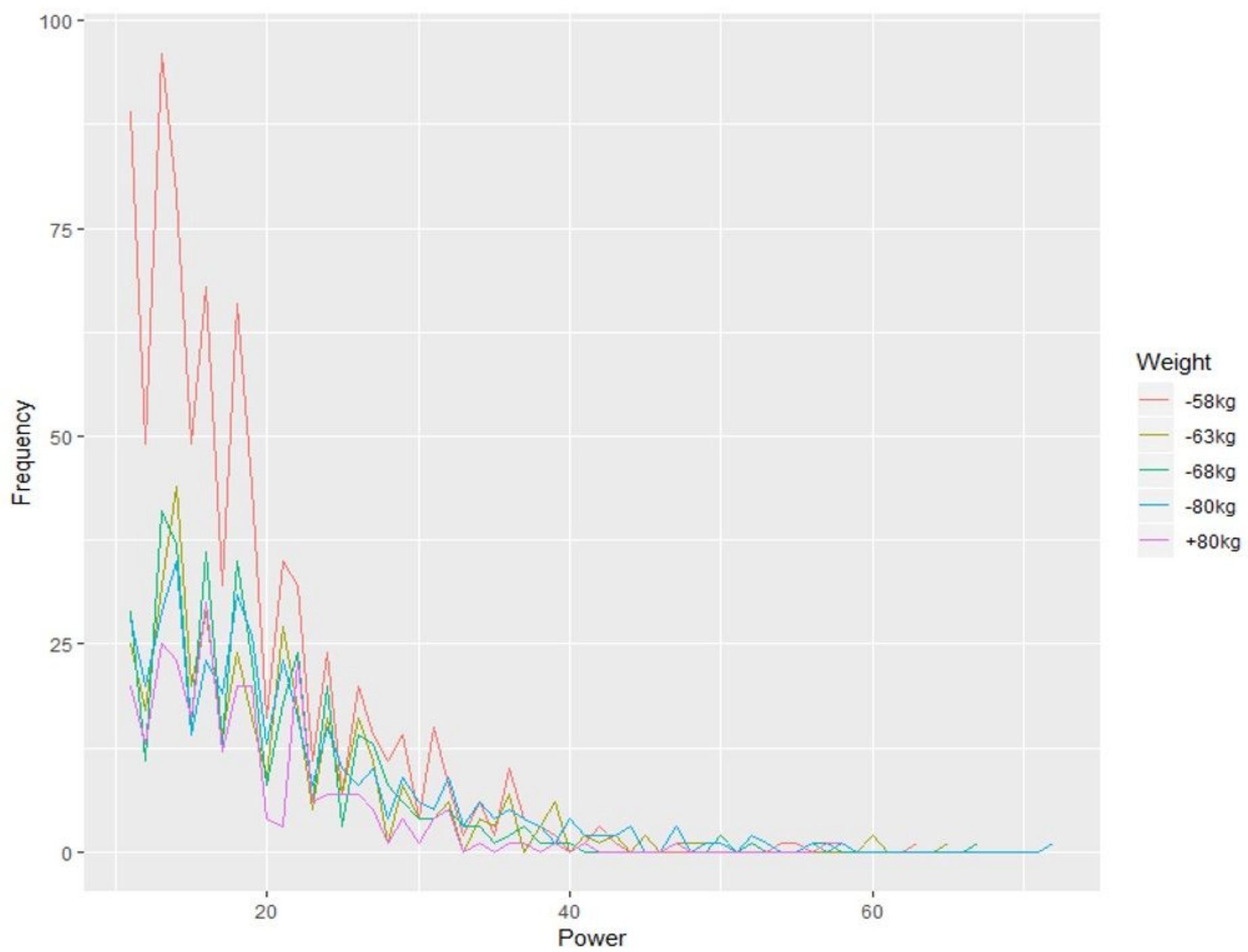

Figure 1

Men's kick impact figures by weight class 


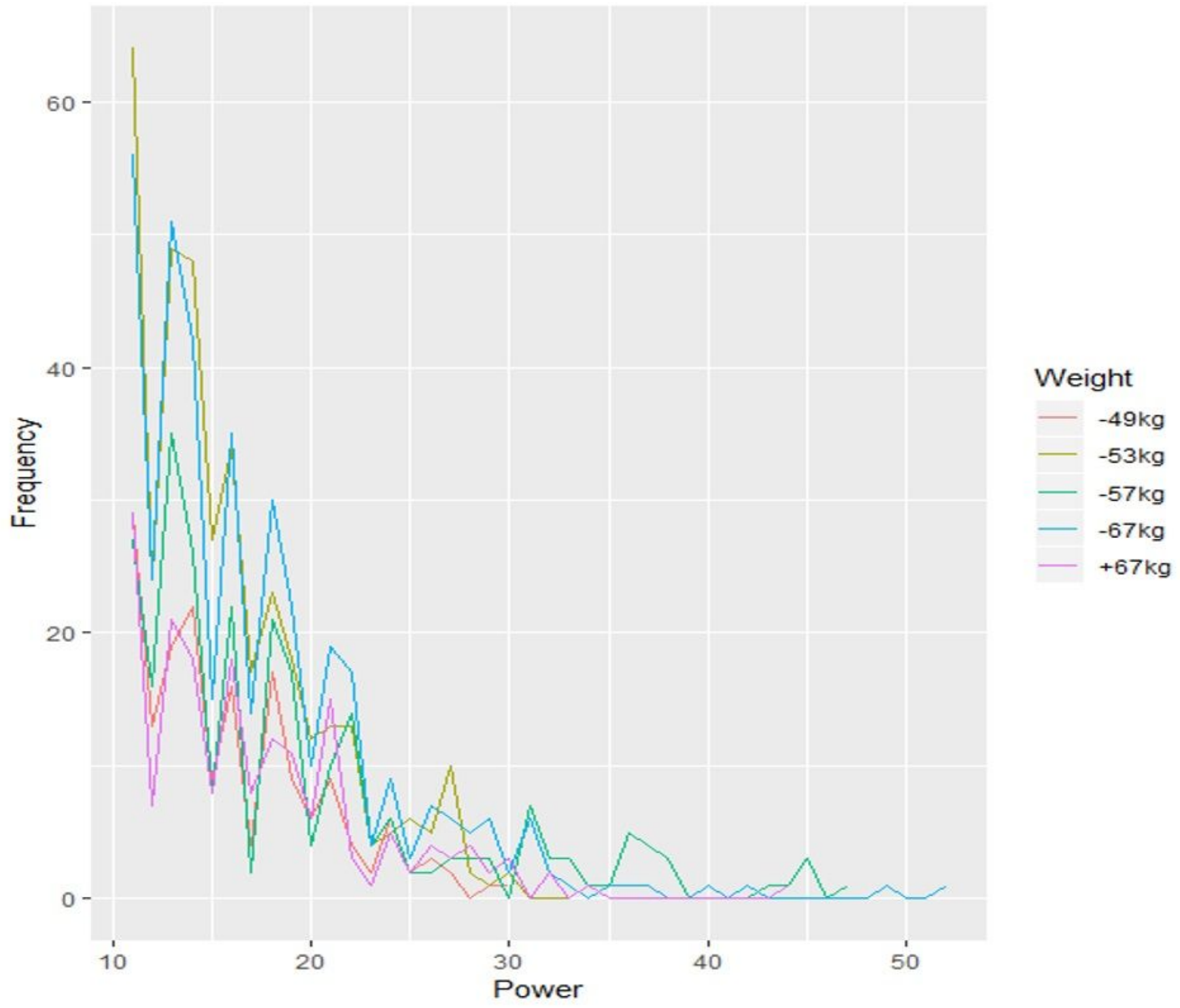

Figure 2

Women's kick impact figures by weight class 